\title{
EDITORIAL
}

\section{Nursing Science}

We are still concerned about the lack of understanding that many have regarding nursing: is it a science or an art? But, reflection about its complexity begins to appear, not as an "enemy" to be eliminated, but as a challenge to be emphasized.

The focus of nursing is the care for human beings; all of its theories emphasize the multidimensionality of the human being and accept that we work with genetic information (heredity), sociological information (cultural), life events and occasional randomness. This combination, in itself, potentially generates conflicts.

Accepting the complexity of our "object of action" does not explain everything, but it awakens us and leads us to explore everything. What is the best way to manage "this" medication in people with "these" characteristics of skin or blood vessels? What better way to do "this" intervention in " $\mathrm{x}$ " location on the body, in people who have "these" social conditions? What better way to comfort "that" person who needs to stay in bed 24 hours, or who just lost a child? What is the best way to appease the desire for someone who wants to eat "a wafer wet in milk", but who cannot swallow? What is the best way to help a mother to breastfeed? What is the best way to help a family to say goodbye to a loved one who is dying? There are so many possibilities and foci of expertise!!

The complexity of care implies the recognition that the multidimensionality of the human being demands of us accuracy and the capacity for interpersonal skills. Accuracy, yes, when we do the calculation of a medication to be administered, as we follow "steps" in performing any aseptic technique, when we expose indicators of falls, the presence of phlebitis, accidental extubation, incidence of pressure ulcers, in nosocomial infection, maintenance time of a catheter ... finally, when we focus on the error with the intention of evolving knowledge. But, the capacity to adequately care also requires us to know who is this "other", this object of our care, what are his powers and limitations, what are his needs, and what contributes to his growth. Likewise, to know what are our own powers and limitations. General and specific knowledge.

Care is a noun that reflects the result of the action of care; and yet, only when there is a therapeutic encounter between the recipient of care and the caregiver is it possible for quality care to exist. Complex!

Complex means that you have a large number of units interacting in ways that are often unpredictable (if not, at a minimum, all medication would function "equally" for all, is it not so?). What happens in the perspective of complexity is an integration in which the parts relate to each other, so this relationship is of paramount importance to the whole. This integration has a subjective character and is based on relational processes, that is, non-linear and, therefore, not always measurable or programmable.

Morin ${ }^{(1)}$ states:

What is the formalizable, quantifiable error of thinking that has dominated the sciences? There is not any way to be a formalized and quantified thought; there is not any way to place in parentheses that which is not quantifiable 
and formalizable. The complete error is believing that what is not quantifiable and formalizable does not exist or is only the dregs of reality. (Morin, 2010, p.188-9)

Understanding science as knowledge and art as skill (the two words of Latin origin), science and art permit you to combine technical competence with dignity, compassion, ethics, and individualization of care. The error may result in an knowledge evolution, in death or in "no evolution". To reduce nursing to quantifiable data, alone, is to limit the human being (and therefore his care) to a "simple notion", negating the complexity of the relations of his dimensions: one is bioanthropologic and biosociocultural.

The measure that a science needs, in the first place, to conquer the objectivity, it conceals the fundamental interests of which not only are the impulses stimulated, but also the conditions of all possible objectivity.

One way of approaching knowledge is to realize that there exists a world around us that is immediately accessible to us, either by the senses or the resources that current technology permits us to create. A mid-level thinker can already perceive that the portion of the world that science (current) allows us to access falls short ${ }^{2}$. (Leme, 2012, p.31)

Even in cases in which science "explains", many times, it is an explanation in the form of theories that change all the time, and thus permits only a temporary false security of knowing what is happening from a macro or microcosmic perspective.

The reality of science is also to be multidimensional, its effects are not simple, they are ambivalent (Example in care? Individuals in prolonged coma are still human beings or are they vegetative?). Another characteristic of science is its "obsession with verifying"; it is one of the rare human activities (maybe the only?!) in which errors are systematically reported and, over time, constantly corrected.

It seems to me that nursing can/should assume the paradigm of complexity as its focus/field of its action; the goal of knowledge is not to discover the secret of the world (or human care) in a master equation of order that would be equivalent to the keyword of the great magicians ("abracadabra!'). The goal is to dialogue daily with the mystery of the world, with the mystery that is us, human beings, with the mystery of how to care so that we can be healthy in the world and with the world. To be the care and the caregiver.

All science is desirable (and laudable), provided it is accompanied by the art and spirituality, without which it transforms into science without conscience (or deficiency). It seems to me especially true with regard to nursing and, of course, the area of health, which deals with the more human side of human beings (bomo sapiens).

In order for nursing to continue anchored in all its beauty and grandeur, we need professionals capable of self-interrogation; self-interrogation, that is, professionals that relate to the one/individual of the art, but also the processes that permit us to reflect and learn from the qualification of the collective evidence from new research by the the actions that need to be precise. Let's continue our professional development, testing new theories, accepting that its falsehood can eventually be demonstrated.

That we combine our science of the complexity exposed in the assertion of the philosopher Pascal: "It is impossible to know the parts without knowing the whole, as it is impossible to know the whole without knowing any particular parts." Or, as our beloved gaúcho (cowboy) poet, Mário Quintana, wrote: "I am large, I fit into contradictions."

\section{References}

1. Morin E. Ciência com consciência. [Science with conscience.] 14 ed. Rio de Janeiro: Bertrand Brasil; 2010.

2. Leme RJ. Saúde é consciência: medicina e saúde x medicina da doença.[Health and conscience: medicine and health vs. medicine of illness.] São Paulo:Ciranda Cultural; 2012.

\section{Profa. Dra. Maria Júlia Paes da Silva}

Full Professor of the School of Nursing, University of São Paulo - USP - São Paulo (SP), Brazil. 